\title{
O equilíbrio entre o comum e o singular e a crítica ao individualismo no pensamento de Hannah Arendt
}

\section{The balance between the common and the singular and the criticism to individualism in the thought of Hannah Arendt}

\author{
ANTONIO GLAUTON VARELA ROCHA ${ }^{1}$ \\ FRANCISCO AILSON ARAUJO CAVALCANTE ${ }^{2}$
}

\begin{abstract}
Resumo: Se, por um lado, o pensamento de Hannah Arendt destaca a importância da singularidade e de uma vida marcada pela liberdade, por outro lado, também afirma a importância da vida humana em relação a uma vida ativa politicamente onde junto com outros nós podemos compartilhar um mundo comum. Buscaremos explicitar, neste texto, como estas duas perspectivas não são excludentes, mas igualmente possíveis em Arendt, exatamente porque o seu pensamento é marcado por um profundo equilíbrio entre o comum e o singular.o em português.
\end{abstract}

Palavras-chave: Singular. Comum. Equilíbrio. Política. Arendt.

Abstract: On the one hand, Hannah Arendt's thought highlights the importance of uniqueness and a life marked by freedom. On the other hand, also affirms the importance of human life in relation, a politically active life where together with others we can share a common world. We will seek to make explicit in this text how these two perspectives are not exclusive, but equally possible in Arendt, precisely because his thinking is marked by a profound balance between the common and the singular.

Keywords: Singular. Common. Balance. Politics. Arendt.

\section{Introdução}

Hannah Arendt foi uma pensadora que buscou reabilitar a política do processo de desgaste que sofreu progressivamente a partir das consequências das grandes guerras mundiais. A força que governos atingiram no mundo coincidiu proporcionalmente à força com que a liberdade foi atacada no mundo inteiro. Considerou-se óbvio que a política em evidência tem como consequência a liberdade em ocaso. A tal diagnóstico, Arendt já apontou, de imediato, uma fragilidade crucial: a confusão entre política e governo ou Estado. Para Arendt, era um erro a ideia de que mais estado ou mais governo era um sinônimo de mais política. O que Arendt vai apontar é que governos fortes podem significar uma efetiva diminuição ou mesmo negação da política. E fora exatamente isso que, segundo Arendt, aconteceu no período supracitado. $O$ que se observou não foi a colocação da política em evidência, mas a retirada da política da existência das

\footnotetext{
Doutorando em Filosofia pela Universidade Federal do Ceará - UFC. E-mail: glautonvarela@gmail.com

${ }_{2}^{2}$ Graduando em Licenciatura em Filosofia pelo Centro Universitário Católica de Quixadá Unicatolica. E-mail: ailsonaraujo208@gmail.com
} 
pessoas. Na realidade, este ocaso da liberdade coincidiu com o forte e brutal ocaso da política. O que nos leva a entender que, para Arendt, existe uma ligação direta entre política e liberdade, chegando Arendt a afirmar que o sentido da política é a liberdade.

Esta visão de Arendt era possível porque ela partia de uma perspectiva diferente de pensar a liberdade. Para os críticos da política que ela enfrentou, a liberdade é algo apenas da esfera individual, privada. A política era vista como algo puramente externo, que interferia na vida privada dos indivíduos. Era algo a ser criticado. Já, para Arendt, a liberdade é algo que se dá entre pares, num contexto relacional. A política representa saída da privatividade, mas, nem por isso, representa risco à individualidade. Veremos que, na leitura de Arendt, é exatamente nesta relacionalidade (que a política favorece) onde a individualidade pode ser desenvolver. Trata-se de uma outra perspectiva como dito acima, uma perspectiva em que o singular não se entende a partir do isolamento de forma que o comum não existe apenas em função do coletivo. Nesta perspectiva, o singular aponta para o comum e o comum para o singular. Em outros termos, é o que significa a tese do equilíbrio entre o comum e o singular.

\section{Sobre o singular e o comum}

Logo de início, entendemos ser importante partir de uma explicação sobre os termos comum e singular na forma como os usamos neste texto. Ao usar a palavra comum, nos referimos às realidades ou dimensões da vida humana que são vividas na perspectiva do compartilhar e do estar juntos. Por exemplo: compartilhamos uma linguagem, compartilhamos um a cultura, compartilhamos referências sociais, compartilhamos um mundo comum.

Ao usarmos a palavra singular, nos referimos às realidades ou dimensões da vida humana que são vividas na perspectiva da individualidade e da unicidade. Temos pontos de vistas singulares; temos características físicas e espirituais singulares; somos um "quem” marcado pela singularidade.

Explicada esta questão, passamos, então, à consideração sobre como essas duas realidades se relacionam no pensamento de Hannah Arendt. Nós defendemos que são duas dimensões que estão em profundo equilíbrio no pensamento político de Arendt. Esta consideração tem como pano de fundo o antigo debate sobre a relação entre o individual e o coletivo, que pode se desdobrar num questionamento sobre a posição de Arendt diante do comunitarismo e do liberalismo.

Neste ponto, destacamos que a nossa questão não se concentra no debate comunitarismo-liberalismo. Não se trata de uma preocupação fundamental para a argumentação que queremos desenvolver a definição de um enquadramento de Arendt numa perspectiva comunitarista ou liberal, mas a referência, mesmo que 
parcial, ao posicionamento de Arendt frente a estas duas correntes de pensamento. Ora, isso já nos dará um bom indício sobre como Arendt se posiciona em relação ao comum e ao singular. Defendemos que Arendt não pode ser classificada como uma comunitarista, exatamente porque o comunitarismo trata a relação comum-singular em desequilíbrio, pendendo muito mais para a realidade comunitária da vida humana. Por motivo similar, ela não pode ser classificada como liberal, pois a balança liberal pesa insistentemente para a dimensão individual do ser humano. $\mathrm{O}$ enfoque afirmativo da pessoa, que podemos encontrar nos dois modelos, é um contrapeso ao risco de se propor um modelo de sociabilidade marcado por um desequilíbrio entre dimensões igualmente fundamentais na vida humana. E, como em todo lugar ou situação em que se reconhece um risco, o reconhecimento de propostas políticas que focam excessivamente o coletivo ou o individual nos exigem atenção. Neste contexto, nossa argumentação se debruça sobre um risco em particular: o individualismo.

Esta contextualização nos permite apontar em que perspectiva nós buscamos apresentar a questão da relação entre o comum e o singular no pensamento de Arendt: tratamos esta relação a partir de uma abordagem anti-individualista do pensamento arendtiano. Para tornar mais clara a nossa colocação é importante salientar que o cerne da nossa pesquisa não é o individualismo. Nossa preocupação fundamental é detectar e evidenciar a presença de uma relação profundamente equilibrada entre o comum e o singular no pensamento político de Arendt. Por isso, buscamos apontar como este suposto equilíbrio se manifesta na sua obra, a partir de temas fundamentais para Arendt, como ação, aparência e especialmente o mundo comum.

A partir da afirmação deste equilíbrio, buscamos apontar como o pensamento de Arendt se posiciona diante do problema do individualismo, tendo em vista que grande parte dos problemas que Arendt denunciou (massificação, abandono do mundo, desertificação) não cessaram com a queda dos regimes totalitários. Se estes problemas não cessaram (e sabendo dos efeitos desastrosos que eles causaram) é preciso buscar entender sob que formas ou suportes estes problemas se manifestam em nosso cotidiano, e, ao mesmo tempo, pensar sobre como podemos nos posicionar diante deles. Refletindo sobre o individualismo, considerando as falas de Arendt e de estudiosos sobre o tema (como Louis Dumont) defendemos que a ideologia individualista é um meio privilegiado através do qual os problemas acima citados continuam a se manifestar em nosso cotidiano. Ao mesmo tempo consideramos que a peculiar compreensão de Arendt sobre a relação entre o comum e o singular nos fornece ferramentas conceituais fundamentais para lidar com os perigos do individualismo.

É preciso explicar também que este mesmo processo poderia ser aplicado ao coletivismo, uma vez que o equilíbrio entre o comum e o singular presente no 
pensamento de Arendt nos fornece uma visão diferenciada e crítica tanto do individualismo quanto do coletivismo. Se nós insistimos sobre o individualismo é porque é ele e não o coletivismo a ideologia que tem perdurado durante os últimos séculos.

\section{O conceito de aparência e o equilíbrio entre o comum e o singular: aportes para uma crítica ao individualismo}

Um tema muito importantes que aqui precisa ser tratado para que possamos explicitar a tese do equilíbrio entre o comum e o singular na obra de Arendt é o tema da aparência. No quadro conceitual arenditiano, aparecer é mostrar-se, exporse, é também demarcar uma posição no mundo. O aparecer, para Arendt é, desde o início, um co-aparecer, uma vez que só se realiza na presença de outros (para os quais apareço). Se o aparecer pressupõe a figura do outro, e todo aparecer é já um co-aparecer, podermos afirmar que o estar junto e o compartilhar de um mútuo ato de aparecer é condição sine qua non para falarmos de ação em Arendt, e consequentemente, para falarmos de singularização em Arendt. Assim,

De fato, para Hannah Arendt a distinção humana só acontece na publicidade, nessa esfera plural, de muitos. Só ali o homem pode aparecer em seu caráter único como um quem e não como uma quididade porque assume uma aparência "explícita, ao invés de se contentar em existir meramente como coisas vivas ou inanimadas". (ANDREIUOLO, 2013, p. 224)

Para Forti (2206, p. 281):

Sem espaço próprio de aparência, a realidade do próprio ser, ou seja, a identidade não pode ser preservada da dúvida. Só entrando no mundo, no espaço público, apenas sendo visto, ouvido e identificado pelos outros, o ator confirma seu próprio quem e vê reconhecida a sua própria identidade. E talvez seja conveniente chamar novamente a atenção para o fato de que a consideração arendtiana da relação indivíduo - espaço público, que não é mais que outra maneira de nomear a relação eu/mundo e eu/o outro, pressupõe, transpondo-a para termos políticos, a crítica heideggeriana a chamada metafísica da subjetividade ${ }^{3}$.

Este conceito é muito importante para Arendt porque ele viabiliza a expressão da singularidade e da unicidade de cada pessoa - o quem cada pessoa é, para além do que se é. A valorização deste quem é fundamental para a rejeição prática de

\footnotetext{
3 "Sin espacio propio de apariencia, la realidad del propio ser, es decir, la propia identidad no puede preservarse de la duda. Sólo entrando en el mundo, en el espácio público, sólo siendo visto, oído e identificado por los otros, el actor confirma su propio quién y ve reconocida la propia identidad. Y quizás sea conveniente llamar de nuevo la atención sobre el hecho de que la consideración arendtiana de la relación individuo-espacio público, que no es más que otro modo de nombrar la reláción yomundo y yo-el outro, presupone, transponiéndola a términos políticos, la crítica heideggeriana a la llamada metafisica de la subjetividad".
} 
qualquer processo de massificação e, em última análise, do totalitarismo (que se empenha em apagar qualquer traço distintivo e qualquer espontaneidade daqueles que são eleitos como inimigos objetivos).

É preciso notar que o conceito de aparência manifesta abertamente o equilíbrio entre o comum e o singular. Eu não tenho como expressar toda a riqueza conceitual deste conceito se me ater apenas ao fato de que o aparecer manifesta $o$ apresentar de uma singularidade, ou se me atenho apenas ao fato de que o aparecer é um co-aparecer porque pressupõe a presença de outros. Não se pode focar exclusivamente sobre apenas um destes lados da aparência sob pena de se cometer uma grave infidelidade ao pensamento arendtiano.

Observemos, então, que essa valorização da singularidade que se nota a partir da importância que o conceito de aparência possui na obra de Arendt não representa um voltar-se para o indivíduo. Trata-se justamente do contrário: a valorização do indivíduo se dá exatamente a partir da saída do interior do indivíduo e o voltar-se para um mundo compartilhado com outros, onde o indivíduo pode aparecer. Neste processo de aparência, forma e fortalece a sua própria singularidade. É o que podemos chamar de individuação dentro da intersubjetividade (Segal, 2016, p. 4). O indivíduo é pensado por Arendt numa perspectiva bastante diferente da vista no contexto liberal. Ao invés de conceber um indivíduo que se desenvolveria no isolamento (o que leva à atomização e o abandono do mundo ${ }^{4}$ ), Arendt concebe um indivíduo que precisa ser pensado num contexto relacional para ser compreendido existencialmente como um ser humano, e não apenas biologicamente ${ }^{5}$. Em Arendt, a intersubjetividade é anterior (Cf. ROVIELLO, 1997, p. 121). Não se diz aqui que o indivíduo não é nada antes de entrar no contexto relacional. A capacidade de espontaneidade e de iniciar algo novo é basicamente individual (Cf. POSSETI, in: GUARALDO, 2008, p. 91). No entanto, cada novo início, enquanto novidade para o mundo humano, só é possível no contexto relacional (Cf. GUARALDO, 2008, p. 69). A própria liberdade, geralmente reivindicada como tema liberal e como direito individual, em Arendt não se compreende como algo que emana da vida privada. Em Arendt, fora de um mundo humano artificial e compartilhado a liberdade não é possível (Cf. ARENDT, 2013, p. 147). A liberdade pertence, antes de tudo, ao terreno da vida pública e não da vida privada. Além disto, se examinarmos as consequências apontadas por Arendt a respeito de uma

\footnotetext{
${ }^{4} \mathrm{~A}$ "[...] excessiva ênfase [do liberalismo] na autonomia e no individualismo leva à atomização e à alienação política, abrindo a porta para a solidão que Arendt descreve como tão perigosa para o político, que torna o controle muito mais fácil para qualquer governo, seja democrático ou totalitário" (TOPOLSKI, 2015, p. 209). "A ênfase na cidadania liberal na expansão dos direitos na esfera privada não serve para remediar a exclusão política, mas, pelo contrário, serve para reproduzir a própria solidão que tornou os indivíduos modernos suscetíveis à dominação totalitária” (GAFFNEY, 2015, p. 2).

5 “[...] seres humanos no verdadeiro sentido do termo só podem existir onde existe um mundo, e um verdadeiro mundo no verdadeiro sentido do termo só pode existir ali onde a pluralidade da raça humana é mais do que mera multiplicação de uma espécie" (ARENDT, 2013, p. 238).
} 
vida exageradamente focada no singular, percebemos que a fuga de um contexto relacional nos afasta progressivamente do que nos distingue como seres humanos até chegar à situação limite da solidão, que explorada "politicamente" pelo totalitarismo nos levou ao extremo do inumano.

Esta observação antecipa um pouco das prováveis conclusões do exercício que tenho feito para compreender a importância da perspectiva do equilíbrio entre o comum e o singular na obra de Arendt: uma nova forma de valorização do indivíduo e da singularidade sob moldes totalmente diversos do individualismo. Esta outra abordagem pressupõe a afirmação de que, em Arendt, a questão do equilíbrio entre o comum e o singular se manifesta na defesa de uma "comunidade da singularidade", conforme a expressão de Roberto Giusti (Cf. 1999, p.67). Esta expressão faz referência a uma situação em que a afirmação da singularidade implica numa afirmação do comum/comunidade, e a afirmação do comum implica na afirmação do singular. Neste sentido, o problema do individualismo não seria a afirmação do indivíduo, mas um modo equivocado (desequilibrado) de afirmar o indivíduo, onde sua afirmação implica a diminuição do comum. No contexto que aqui foi chamado de "comunidade da singularidade", a afirmação do singular representa uma afirmação conjunta do comum, o que aponta tanto para uma nova forma de valorizar o indivíduo, como uma nova perspectiva de abordagem crítica ao individualismo.

Dito isto, podemos afirmar que a nossa busca pela explicitação do referido equilíbrio começa por identificar as críticas de Arendt ao retorno exagerado do indivíduo sobre si mesmo, e a tendência de abandono do mundo ou alienação do mundo. Um dos primeiros momentos em que Arendt trata deste problema é na obra Rahel Varnhagen - A vida de uma judia alemã na época do Romantismo, que foi a segunda obra de Arendt (a primeira foi sua tese sobre o amor em Agostinho). Tratase de uma obra que geralmente não é muito explorada nos estudos sobre Arendt, mas que consideramos muito importante porque nela Arendt antecipa algumas questões que serão cruciais para o desenvolvimento do seu pensamento.

\section{A crítica à instrospecção e o processo de assimilação na leitura de Arendt sobre Rahel Varnhagen}

A obra tem como problema central a questão da assimilação judaica. A apresentação da vida de Rahel Varnhagen expressa o dilema vivido pelos judeus diante de um quadro de exclusão em que viviam e da possibilidade que se abria para fuga desta exclusão através da assimilação dos valores da sociedade em que estavam. A grande questão era decidir qual atitude tomar diante deste dilema: negar a si próprio para ganhar aceitação ou resistir e questionar a situação da vida judaica na época. Para romper com esta realidade, Rahel irá inicialmente tornar-se parvenu. "Rahel desejava escapar ao judaísmo; não parecia haver qualquer outra maneira de 
assimilar-se" (ARENDT, 1994, p.33), assim, ela “... casou-se com August Varnhagen, aos 43 anos, quando foi batizada e adotou um novo nome: Antonie Friederike Varnhagen" (Rapchan, 2004, p.313). Ao se converter ao catolicismo fará uma verdadeira "conversão" daquilo que era, deixando de ser si mesma e renunciando a tudo que a identifique como judia.

Com esta biografia, referida a um período crucial da assimilação dos judeus, Arendt tentou demonstrar, através de Rahel Varnhagen, o drama que supôs o abandono da identidade judaica em favor da assimilação social e intelectual, e a forma como esta assimilação influencia de maneira determinante sobre o destino individual de um ser humano. A alternativa não deixava de ser dramática: ou a assimilação como parvenu, mesmo à custa de perder a dignidade e saber que um seria considerado na realidade como um "parasita", ou manter a dignidade sob a condição de pária . (BÁRCENA, 2006, p. 184)

A assimilação efetivava "[...] a atomização das comunidades em indivíduos solitários" (ARENDT, 2016, p.98). Esta individualização não seria uma efetivação da singularidade junto aos outros (o aparecer), mas a separação de indivíduos em relação a um grupo determinado para posterior diluição na sociedade em que almejavam participar. Era uma atomização por meio do cultivo da personalidade, onde o individualizar-se era tornar-se um igual (Cf. RAPCHAN, 2004, p.303).

Este processo (de individuação atomizada usada como passo para a assimilação) que Arendt irá apresentar e criticar em sua Biografia de Rahel Varnhagen acontece a partir dos ideais iluministas - dos quais o romantismo é a continuação (Cf. ARENDT, 2016, p. 114). No centro da estratégia romântica está a "...introspecção, em uma atitude reflexiva na qual o mundo é negado em sua objetividade" (ADVERSE, 2013, p. 85) em favor da interioridade. Por meio da introspecção, a negação da realidade externa era alimentada em nome de uma "nova realidade" mais reconfortante. No caso do judeu que buscava a assimilação, esta realidade mais reconfortante era a aceitação social, o fim das injurias que sua condição de judeu o trouxe como herança. Trata-se da busca do eu profundo, que no contexto do romantismo, só se alcançava como um retorno cada vez mais íntimo ao próprio interior. O problema desta postura será que o indivíduo terá ao final abandonado o mundo, um abandono que Arendt mostrará ser muito perigoso do ponto de vista político.

\footnotetext{
6 "Con esta biografía, referida a un periodo crucial de la asimilación de los judíos, Arendt pretendió poner de manifiesto, a través de Rahel Varnhagen, el drama que suponía el abandono de la identidad judía en beneficio de la asimilación social e intelectual, y la forma en que esta asimilación influye de manera determinante en el destino individual de un ser humano. La alternativa no dejaba de ser dramática: o la asimilación como parvenu, aun a costa de perder la dignidad y de saber que uno sería considerado en realidad como un "parasito", o mantener la dignidad bajo la condición de paria".
} 
Eis então o traço distintivo da individualidade romântica. Para além do caráter anedótico da vida de seus representantes, o individualismo romântico implica um abandono do mundo como o espaço intersubjetivo para a ação: a subjetividade do indivíduo isolado o fragmenta em inúmeras cristalizações das disposições de ânimo. Do ponto de vista político, trata-se de uma catástrofe porque corresponde a abrir mão da variedade de lados que compõem a realidade, juntamente com a perda de interesse pelo mundo. (ADVERSE, 2013, p.87)

Sua fala sobre a introspecção tem um caráter eminentemente político. Nela, Arendt antecipa sua argumentação a respeito da confusão entre os domínios do público e do privado, evidenciando as diferenças entre os dois caminhos apresentados ao judeu na condição de pária: seguir como um assimilado, o judeu parvenu, que nega a própria identidade, ou seguir como paria consciente, que reafirma sua identidade, sua singularidade, procurando demarcar um espaço mesmo num mundo que lhe é hostil. O parvenu tenta resolver de modo individual e isolado um problema que é de seu grupo; o paria consciente enfrenta o desafio de posicionar-se publicamente, e ao se expor sai da perspectiva puramente individual. Há aqui uma clara rejeição de uma postura individualista isolada do romantismo que é presente no processo de introspecção e no culto à personalidade.

A partir deste processo de introspecção romântica vivenciado por Rahel Varnhagen podemos destacar duas questões importantes para o pensamento político de Arendt: 1) Arendt critica a busca "quem" se é através de um retorno a si mesmo, na interioridade do indivíduo, em Arendt o quem se encontra num processo contrário ao proposto na introspecção, para Arendt a singularidade se manifesta e se forma na saída de si mesmo e no encontro com outros, no ato de aparecer (ou coaparecer). É neste posicionar-se no mundo que se manifesta e se constrói o "quem" de cada pessoa. 2) Também se destaca o alerta de Arendt sobre o perigo da perca da realidade manifesta no esforço da introspecção. Identificamos aqui a possibilidade de traçar um paralelo com a perca da realidade no interno do totalitarismo através da disseminação da ideologia, onde a realidade também era negada em troca de uma "realidade alternativa" fabricada. Assim como na introspecção romântica há aqui um abandono do mundo, situação que para Arendt ampliava ainda mais a perca do contato com a realidade daqueles que eram manipulados pela ideologia totalitária.

\section{Conclusão}

Este texto não tem pretensão de esgotar a tese do equilíbrio entre o comum e o singular, mas os elementos aqui lançados nos permitem perceber que importantes categorias arendtianas apontam para o referido equilíbrio. Aqui tratamos do conceito de aparência e junto a ele o processo de singularização. É muito pertinente avaliar, com mais profundidade, o modo peculiar como estas categorias tratam 
tanto o aspecto do comum quanto o aspecto do singular como fundamentalmente importantes. O que nos leva a apontar para a conclusão (mesmo que ainda de modo prévio) de que estamos diante de um modo diferente de valorização das dimensões da individualidade e do comum. Trata-se de uma valorização que não isola tais conceitos, mas que se dá exatamente no momento em que o singular aponta para o comum e o comum aponta para o singular. Neste sentido, os caminhos que levam à valorização exclusiva de apenas uma destas dimensões se mostra como prejudicial, causando exatamente o desequilíbrio entre o singular e o comum. A introspecção romântica, como denunciada na obra de Arendt sobre Rahel Varnhagen nos ajuda a entender os riscos deste desequilíbrio.

\section{Referências}

F Adverse, H. "Arendt e a crítica ao romantismo na biografia de Rahel Varnhagen”, in: Argumentos, ano 5, n. 9 - Fortaleza, jan./jun. 2013.

Andreiuolo, B. “Os homens do mundo e a diferença entre que e quem", in: Argumentos, ano 5, n. 9 - Fortaleza, jan./jun. 2013.

ARENDT, H. Escritos judaicos. Barueri: Amarilys, 2016.

. A promessa da política. 5 ed. Rio de Janeiro: Difel, 2013.

. Rahel Varnhagen - A vida de uma judia alemã na época do Romantismo. Rio de

Janeiro: Relume-Dumará, 1994.

FORTI, S. Hannah Arendt: tra filosofia e política. Milão: Bruno Mondadori, 2006.

Gaffney, J. "Another Origin of Totalitarianism: Arendt on the Loneliness of Liberal Citizens", in: Journal of the British Society for Phenomenology, 2015.

GIUSTI, R. Antropologia della Libertà - A comunità delle singolarità in Hannah Arendt. Assisi: Cittadella Editrice, 1999.

GUARALDO, O. Il Novecento di Hannah Arendt: un lessico politico. Verona: ombre corte, 2008.

Rapchan, E. S. "Hannah Arendt - Rahel Levin: duas biografias, sujeito e espelho", in: Cadernos pagu (22) 2004: pp.291-327.

ROVIELLO, A-M. Senso comum e modernidade em Hannah Arendt. Lisboa: Instituto Piaget, 1997.

SEGAL, J. "A 'delight in doing' individuality and action in the political thought of Hannah Arendt". The New England Journal of Political Science, v.2, n.2, 2016.

Submissão: 05.02.2019/Aceite: 14.08.2019 